\section{Apuntes para una semblanza intelectual de Jesús Martín Barbero}

\author{
Por Beatriz Jaime Pérez
}

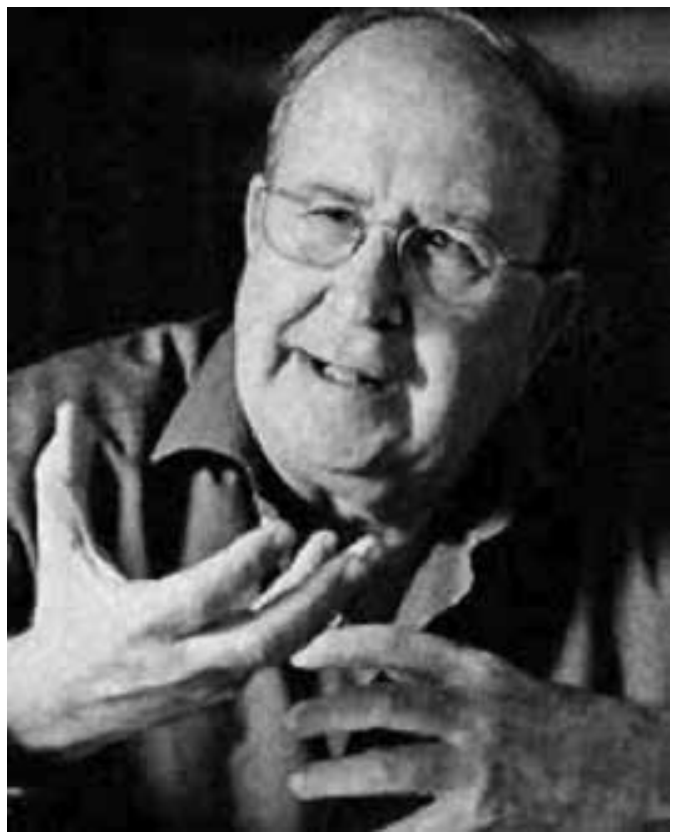

Entre los investigadores de la comunicación y la cultura latinoamericana de finales del siglo XX y de lo que va corrido del XXI, Jesús Martín Barbero es quizá el intelectual más influyente. El quiebre epistemológico que ha planteado para estudiar a la cultura popular es tan categórico, que difícilmente un investigador que se dedique a estos estudios podría pasarlo por alto. Incluso para quienes no comparten sus apuestas teóricas es inevitable su referencia.

Sus múltiples publicaciones dan cuenta de los variados temas sobre los que el profesor Martín Barbero ha puesto su interés académico. El espectro es tan amplio que de este autor se pueden encontrar estudios o reflexiones sobre educación, política, jóvenes, nuevas y viejas estéticas; por supuesto, medios de comunicación, tradicionales y de vanguardia, vistos siempre con una perspectiva centrada en la comunicación y la cultura.

Es preciso advertir, antes de continuar, que lo desarrollado en este texto es apenas un esbozo con el que se podría empezar a componer una semblanza intelectual de Jesús Martín Barbero. De ahí la necesidad de no perder de vista la primera palabra del título: Apuntes. Mal podría decir que soy especialista en el pensamiento de este autor, cuando no he leído toda su obra, aunque por razones de mi oficio (docente de un programa de comunicación social) lleve algunos años relacionándome con sus estudios.

Entonces, lo que anima estos Apuntes es mi interés por la semblanza. Este género resulta apropiado para narrar aspectos reveladores y selectos de personajes contemporáneos, además de ser un instrumento útil para la difusión del conocimiento. Claro que el personaje en sí mismo también constituye una motivación en este trabajo, y no solo por su estatura intelectual, sino porque el profesor Martín Barbero es depositario de un temperamento seductor, casi festivo, en cuya conversación, tan excelsa siempre, hay una suerte de humor y de ironía que la hacen muy amena. $\mathrm{O}$ al menos este es el recuerdo más vivaz que tengo de cuando tuve el gusto de conocerlo y de ser su alumna.

Bien, las referencias permanentes que atraviesan la obra del profesor Jesús Martín Barbero están hechas fundamentalmente de experiencias personales y cotidianas. Es decir, el marco teórico entregado por Freire y Gramsci; Ricoeur y Heidegger, Adorno y Benjamin; Merleau-Ponty y Serrano y la larga lista de reputados autores a partir de los cuales comenzó a construir su pensamiento, no habría encontrado asidero ni le habría servido para abrir

BEATRIZ JAIME PÉREZ. Comunicadora Social-Periodista, Magistra en Comunicación y docente de la Facultad de Ciencias Humanas y Artes de la Universidad del Tolima. 
un campo de estudio novedoso sobre la comunicación si no hubiera mirado con especial interés lo que otros intelectuales miraban con desprecio: la cultura popular.

"Qué es lo que ellos ven, que yo no veo", se preguntó a mediados de los años setenta, cuando una tarde en Cali, sorprendido por el éxito de una película que llevaba seis meses en cartelera, se fue a verla. Era La ley del monte. El profesor Martín Barbero ha narrado esta historia en múltiples espacios, pero la versión más graciosa la recoge en la introducción de su libro Oficio de Cartógrafo. Travesías latinoamericanas de la comunicación en la cultura, publicado en 2002.

El hecho es que no pudo evitar las carcajadas al poco de iniciado el filme, pues solo "en clave de comedia podía ver ese bodrio argumental y estético", según sus propias palabras. Lo que vino después fue el reclamo de unos hombres, que, ofendidos por la risa, amenazaron con sacarlo de la sala si no guardaba silencio. Primero avergonzado y después sorprendido por la reacción de aquellas personas, el profesor enmudeció y decidió permanecer en la sala, pero ya no para ver la película sino para observar a la gente que seguía con embeleso la trama que le estaban proyectando.

Esa experiencia le otorgó lo que él ha denominado su primer "escalofrío epistemológico". Ese estremecimiento lo llevó a detectar un tema poco o nada explorado en América Latina: la recepción, los usos y los consumos. La investigación en comunicación había entregado sus mejores esfuerzos al estudio del mensaje en los medios masivos. Pero puesta la mirada en la recepción y los usos, el profesor Martín Barbero había comenzado a abrir un campo de estudio en torno a la cultura, la antropología y la comunicación, que de acuerdo con la investigadora mexicana Rossana Reguillo, resultaba novedoso y fundamental, pues con su trasfondo filosófico, les otorgaba densidad y perspectiva histórica a las preguntas que desvelan la realidad latinoamericana.

El profesor ha confesado sin recato, en entrevistas, en clase, o en sus múltiples publicaciones, que cuando comenzó a escribir sus mapas sobre los procesos de comunicación y de cultura no tenía mucha claridad sobre lo que estaba diciendo. El único aspecto claro era su pregunta de investiga- ción: ¿`Por qué disfruta la gente donde los intelectuales nos aburrimos?

Así llegó al estudio de la cultura popular y con ella a la televisión y particularmente a la telenovela. En la década de los ochenta se dedicó, con el grupo de profesores del Departamento de Comunicación de la Universidad del Valle, a investigar la manera como en la telenovela colombiana se articulan las intenciones comerciales de su producción con las lógicas culturales de su consumo.

Algunos avances de esta investigación fueron publicados en Colombia y otros países de América Latina, pero el producto más excelso lo constituye la publicación del libro titulado Televisión y melodrama. Géneros y lecturas de la televisión en Colombia (1992). En él, el profesor Martín Barbero expresa que el melodrama es la fórmula comercial ganadora en las telenovelas, porque en ellas se manipulan sentimientos básicos como el miedo, el entusiasmo, la lástima y la risa, a través de la óptica claramente marcada de personajes como el traidor, el justiciero, la víctima y el bobo. Pero también porque la telenovela recupera las anacronías de discursos tradicionales, e incluso arcaicos, y las mezcla con las transformaciones de las masas urbanas, cuya oralidad ha incorporado las gramáticas audiovisuales. En ese mestizaje reside el secreto y la fascinación que ejerce la telenovela, asegura.

Pero por esa misma razón -continúa el profesor- la empatía y la seducción que la telenovela suscita entre los sectores populares, o sea, entre las mayorías, es directamente proporcional al asco y al rechazo que produce entre las élites, porque para los críticos más ilustrados, la telenovela no alcanza ni siquiera el estatuto de ficción.

De acuerdo con Reguillo, Martín Barbero supo encontrar con esa profundidad antropológica que lo caracteriza, las diversas maneras como esta comunicación se ancla en las culturas populares, con lo cual se logra expresar no solo la alienación y el atontamiento que ven algunos críticos, sino también hondas preocupaciones políticas y cotidianas que el lenguaje político no logra captar. Ello significó, dice Reguillo, una importante transfiguración en el modo de encarar la pregunta por la comunicación y permitió incorporar, con estatuto epistemológico, una diversidad de objetos culturales que habían sido expulsados por 
unas ciencias sociales demasiado normativas. Esta apertura sacudió los cimientos sobre los que se asentaba una clasificación que impedía encontrar los puntos de contacto, colaboración y resistencia entre la cultura de masas, la cultura popular e incluso la llamada cultura "erudita".

En la compilación hecha por Daniel Mato, titulada Cultura, Politica y Sociedad. Perspectivas latinoamericanas, publicada por Clacso en el 2005, el profesor Martín Barbero dice que la telenovela colombiana juntó y mezcló los diversos países que conforman a este país. Es decir -agrega el profesor- visibilizaron el desencuentro nacional con lo regional, la centralización desintegradora de un país plural, y la lucha de las regiones por hacerse reconocer como constitutivas de lo nacional.

Sin embargo, esa capacidad que el profesor Martín Barbero les otorga a las prácticas cotidianas de la cultura popular para fortalecer comunidades, también ha motivado cuestionamientos, como era de esperarse.

Néstor García Canclini, en Mapas nocturnos. Diálogos con la obra de Jesús Martín Barbero(1997), ${ }^{1}$ dice que las ideas de este autor sobre la cultura popular no alcanzan a responder por qué los sectores populares participan eufóricos en espectáculos televisivos que los humillan y dan consenso a políticos que preservan la explotación.

En el conversatorio titulado La presencia de Jesús Martín Barbero en la Universidad del Tolima ${ }^{2}$, realizado en Ibagué en agosto del año pasado, el profesor Pierre Díaz Pomar, ponente, habló en este mismo sentido, al preguntarse cuáles serían los actos transgresores y contra-hegemónicos de los sectores populares que Martín Barbero observó en su investigación y valoró como un ejercicio de insurgencia cultural.

Para el profesor Díaz Pomar, con esa mirada a los sectores populares se corre el riesgo de caer en el esencialismo, aunque al mismo tiempo valora el hecho de que Martín Barbero rompa en forma categórica con una tradición epistemológica que por décadas creyó idiota a las gentes que conforman la cultura popular.

Como se ha dicho antes, Martín Barbero encuentra objetos de estudio en su propia experiencia personal y familiar, sobre todo en las más anecdóticas. Pues bien, así como los hombres que lloraban de emoción viendo La ley del monte le causó un profundo estremecimiento, el desarrollo de la teoría de las mediaciones también se relaciona con un momento de conmoción similar.

En Oficio de cartógrafo, el profesor narra el largo silencio que provocó una respuesta suya, cuando en el primer congreso internacional organizado por Felafacs (Federación Latinoamericana de Facultades de Comunicación Social) en Lima, 1982, titulado Comunicación y poder, las ponencias de los invitados, investigadores de toda América Latina, versaron no tanto sobre la relación entre comunicación y poder, sino sobre el poder de la comunicación.

El profesor, que venía de haber estado un año en Europa documentándose sobre las matrices populares de lo masivo, centró su exposición en la no contemporaneidad entre las tecnologías de comunicación y sus modos de uso en América Latina. Habló, entonces, de las formas populares de la esperanza, la relación entre las formas de sufrimiento y las formas de rebelión popular, su religiosidad, su melodramatismo y sus movimientos de resistencia y de protesta.

Al terminar su ponencia, una voz escandalizada le preguntó por qué mientras todos los conferencistas habían hablado del poder de los medios que hoy constituye la tecnología, él se había dedicado a hablar de lo popular. Y remató increpándolo con esta pregunta: ¡cuál es su obsesión con lo popular?

El profesor, que confiesa haber respondido en forma impensada, pero que luego su respuesta le dio mucho qué pensar, le dijo: "Quizá lo que estoy haciendo cuando en la investigación valoro tan intensamente lo popular, es rendir un secreto homenaje a mi madre".

1. Al cumplirse el décimo aniversario del libro De los medios a las mediaciones, la Universidad Central de Bogotá reunió a un grupo de académicos para discutir en torno a la obra de Jesús Martín Barbero, cuyo producto fue la compilación de dieciséis artículos.

2. En el desarrollo del seminario sobre Teoría de la Cultura, el 13 de agosto de 2012, la Facultad de Ciencias Humanas y Artes de la Universidad del Tolima realizó un conversatorio sobre el pensamiento de Jesús Martín Barbero, en el que se presentaron siete ponencias. 
El silencio fue total. Al prolongarse tanto ese que ya no era un silencio sino un bache, el profesor cayó en la cuenta de la profunda sorpresa que había en esa respuesta para sí mismo. En adelante se dedicó a estudiar la relación entre la des-ubicación que su misma posición teórica le acarreaba y la sorpresa que a él mismo le causaba esa posición. De ese estremecimiento y de haber aprendido de Gramsci que "sólo investigamos de verdad lo que nos afecta", nació su obra insigne De los medios a las mediaciones, cuya primera edición fue publicada por la Editorial Gustavo Gili en 1987.

En este texto, el profesor entrega una aproximación conceptual con la cual se puede abordar empíricamente el estudio del consumo. De acuerdo con el sociólogo chileno Guillermo Sunkel, Martín Barbero llega al tema del consumo por el camino de la crítica al "mediacentrismo"; es decir, el profesor desarrolla una concepción de consumo que permite comprender cómo se apropian las culturas populares de los usos sociales de la comunicación.

De ahí que el profesor se exprese en De los medios a las mediaciones así:

[...] el consumo no es sólo reproducción de fuerzas, sino también producción de sentidos: lugar de una lucha que no se agota en la posesión de los objetos, pues pasa aún más decisivamente por los usos que les dan forma social y en los que se inscriben demandas y dispositivos de acción que provienen de diferentes competencias culturales (Martín Barbero,1987, p. 231).

Al identificar el consumo como "producción de sentido", el profesor reivindica las prácticas de la vida cotidiana de los sectores populares. Siguiendo a Sunkel, esta contribución ha sido fundamental porque con ella se detectó la importancia de la temática del consumo en un momento en que la preocupación dominante en los estudios sobre cultura y comunicación en América Latina todavía era el análisis de los mensajes en los medios masivos en tanto soportes de la "ideología de la dominación".

Sin embargo, en el conversatorio al que ya se hizo referencia, celebrado en la Universidad del Tolima, el profesor Díaz Pomar estimó que esta capacidad de recepción activa que el profesor Martín Barbero le endilga a la cultura popular, no alcanza a constituirse en un escenario real de transgresión de ese bombardeo mediático que día tras día hacen los medios de comunicación, sino que más bien parece una retórica de la resistencia que, además, ha dejado muy "mal parado" al sector popular, pues lleva décadas resistiendo mensajes sexistas, racistas, excluyentes, bárbaros, irracionales, etc.

Claro está que el profesor Martín Barbero, en trabajos posteriores ha hecho relecturas de sus posiciones, como diría Néstor García Canclini, $y$ ha reconocido que en los espacios abiertos a los sectores excluidos en la llamada comunicación alternativa hay una visión maniquea y marginalista, cargada de residuos puristas y populistas. $Y$ en este sentido, nuestro autor ha sido más explícito al explicar que el espacio a partir del cual es posible comprender la interacción entre la producción y la recepción no responde solo a requerimientos del sistema industrial y a estrategias comerciales sino también a exigencias que vienen de la trama cultural y de los modos de ver.

Ahora bien, el otro campo de la comunicación en el que el profesor Jesús Martín Barbero ha puesto su interés investigativo es el que tomó forma en los años noventa con la relación comunicación/ educación.

Fue a partir de las lecturas del educador brasilero Paulo Freire y de la antropóloga norteamericana Margaret Mead, pero sobre todo de lo que les escuchaba a sus estudiantes en su propia experiencia como educador, que el profesor Martín Barbero introdujo en sus análisis el tema de la educación.

La familia, la Iglesia y la escuela son las instituciones modernas en las que se han sostenido las sociedades. Pero la escuela ${ }^{3}$, dice el profesor Martín Barbero, es la más profundamente afectada en la sociedad contemporánea y las razones están asociadas a tres aspectos fundamentales: primero, las mutaciones que ha sufrido el conocimiento, que dejó de ser monopolio de la escuela y ahora circula por fuera de ella, rompiendo así las fronteras que separaban los conocimientos académicos del saber común; segundo, el advenimiento de un nuevo sujeto cuya identidad es la de un individuo que sufre una constante inestabilidad identitaria y una fragmentación de la subjetividad cada día mayor;

3. Para el autor, debe entenderse por escuela la educación que se imparte en las instituciones educativas en cualquiera de sus niveles (primaria, secundaria, universitaria). 
y, tercero, la adopción que los sistemas educativos hicieron del concepto de "competencia", cuya idea es la que se mueve en la lógica del competir más que en las dinámicas del crear y de la adquisición crítica del conocimiento.

Para Martín Barbero, los modos de circulación del saber, cuyo movimiento siempre había estado centralizado territorialmente, controlado a través de dispositivos técnicos y manejado por personas socialmente muy importantes, han sufrido mutaciones gracias a la revolución tecnológica.

El profesor plantea que existe una distancia muy grande entre los saberes-lectivos que imparten los maestros en la escuela y los saberes-mosaico que circulan en espacios distintos a ella. Es decir, mientras el medio ambiente comunicativo que rodea a los estudiantes está cada vez más relacionado con esos saberes-mosaico, la escuela se encierra en su propio discurso institucional, pues se tiene la creencia de que aceptar otro sería un atentado contra su autoridad.

Dice el profesor que lo ocurrido a los saberes se explica con base en dos cambios claves: descentramiento y deslocalización temporal. El primero, significa que el saber se ha salido de los libros y de la escuela y eso ha logrado des-centrar la cultura occidental de su eje letrado, cuyo modelo de aprendizaje basado en la linealidad y la secuencialidad no había sufrido modificaciones desde la invención de la imprenta. El desconcierto que ha provocado esta mutación es descifrado por gran parte del mundo escolar en forma moralista, razón por la que se culpa a la tecnología de que los jóvenes no se interesen por la lectura de libros. El segundo, logró que los saberes escaparan de los lugares y de los tiempos legitimados socialmente para la distribución y el aprendizaje del saber. Desde la época de los faraones, dice el maestro, el tiempo de aprender se hallaba acotado a una edad, lo cual facilitaba su inscripción en un lugar y su control vital. Y si bien el lugar escolar no va a desaparecer, sí se ha desligado de la edad y se ha tornado continuo, es decir, a lo largo de toda la vida. La deslocalización también ha implicado el emborronamiento de las fronteras que los separaban del saber común.

En cuanto al advenimiento de un nuevo individuo, Martín Barbero señala que en el racionalismo moderno el sujeto se identificó con una idea de conocimiento que hacía referencia a la capacidad de pensar y razonar; en cambio el sujeto de hoy no tiene un solo mapa de referencia con el que se identifique sino que posee múltiples ámbitos de pertenencia que lo obligan a desempeñarse en diferentes espacios, oficios y roles.

Para el profesor Martín Barbero, el sujeto actual es más frágil, más quebradizo, pero paradójicamente más obligado a asumirse, a hacerse responsable de sí mismo en un mundo en el que las certezas en los planos del saber, de la política, de la ética, entre otros, son cada vez menores.

El tercer aspecto que ha afectado a la escuela, de acuerdo con nuestro maestro, es la adopción del concepto de competencia. Para el autor, esta noción, venida del campo de la lingüística, está asociada a la idea de destreza intelectual, y esta a la de innovación, o sea a la creatividad. Pero en el mundo de la reingeniería empresarial, competencia significa destreza para la rentabilidad y la competitividad y esta última significación es la que se ha vuelto hegemónica en el mundo académico, imponiéndose incluso por encima de la solidaridad.

En múltiples escenarios académicos el profesor Martín Barbero ha descrito esto que él denomina la crisis de la educación y una de sus conclusiones consiste en que mientras los maestros no escuchen a sus alumnos, no van a enterarse de lo que está pasando en el mundo y en la cultura, porque la sociedad llega a las instituciones educativas en forma de cuerpos y almas que son los grupos estudiantiles.

Alguien podría leer esta invitación como un acto de demagogia del profesor. Sin embargo, cuando cursé la maestría en Comunicación, entre los años 2003 y 2004 en la Universidad Javeriana, tuve la ocasión de ser su alumna en un seminario sobre ciudad, denominado Travesías, ciudadanías y urbanias. La clase, que duraba cuatro horas, estaba programada de 5:00 p.m. a 9:00 p.m. Al entregarnos el programa del seminario, el profesor Martín Barbero nos propuso un receso a las 7:00 p.m., lo cual encontramos razonable, pues una clase de cuatro horas seguidas es un exceso para cualquier estudiante colombiano; sin embargo, el receso nunca se cumplió o, por lo menos, no en rigor. Llegadas las 7:00 p.m., o el profesor estaba exponiendo con extraordinario sentido del humor y de la ironía y entonces todos olvidábamos el receso, porque escucharlo era uno de esos goces que 
raras veces se experimenta en las aulas de clase, o era el profesor quien escuchaba a un estudiante y entonces nadie osaba interrumpirlos. Pero cuando eventualmente el profesor recordaba que debía hacer una pausa, salíamos con él hacia el pasillo y allí continuábamos la conversación. Es decir, en sentido estricto el descanso nunca se dio.

Nos hacía reír a mandíbula batiente, para decirlo con la expresión usada por Oriana Fallaci, en una de sus famosas entrevistas. Así pasábamos las cuatro horas de clase, que en realidad tampoco eran cuatro porque nunca terminábamos a las 9:00 p.m., pues a las 9:20 p.m. o 9:30 p.m. debía asomarse el celador del edificio para recordarnos que ya era tiempo de salir.

Alguna vez el profesor Germán Rey, quien lo aprecia mucho, nos dijo a manera de queja que el profesor Martín Barbero no era tratado con la consideración que ameritaba su dignidad y prestigio, y para hacer más gráfica su crítica dijo entonces que la Universidad debería tender un tapete a su paso.

Recuerdo que en ese momento me sentí avergonzada de que algo así estuviera pasando, pero luego pensé que nada le habría parecido más ridículo al profesor Martín Barbero que un tratamiento diferenciado, pues la imagen que tengo de él es la de un hombre sencillo, humilde, no solo con el conocimiento sino también con su figura personal, y que más bien prefiere mezclarse entre los estudiantes a quienes escucha con atención y cita sin prejuicios en sus publicaciones, conferencias o clases.

En el reconocimiento que la Universidad de Antioquia le hizo al otorgarle el título de Doctor honoris causa en Ciencias Sociales, la investigadora
Rosana Reguillo dijo, entre muchas otras cosas, que el profesor Jesús, como maestro, ha significado un estímulo muy importante para numerosas generaciones de estudiantes de las diversas áreas de las ciencias sociales, porque su obra sigue dando frutos no solo a través de su propia intervención docente sino a través de los estudiantes que nos formamos con él de manera directa o indirecta y que fuimos tocados por su capacidad de entrega, de compromiso docente y ese genuino interés por el otro y por la otra.

El profesor Martín Barbero ha recibido múltiples distinciones que superan los cinco títulos de Doctor honoris causa que le han entregado universidades latinoamericanas por sus aportes al estudio de la comunicación y la cultura, hasta reconocimientos en incontables entrevistas, publicaciones de estudios y reflexiones sobre su obra, por supuesto reseñas críticas, homenajes en actos académicos, entre muchas otras formas que han encontrado las universidades de América Latina para agradecerle a este maestro su contribución a las ciencias sociales.

Estos Apuntes son un homenaje más a este investigador que, aunque nació en España, es latinoamericano de corazón y colombiano por adopción, nacionalidad que obtuvo en el 2004 y que le agradece al país por varias razones, pero sobre todo porque fue aquí donde se volvió latinoamericano y también porque el trabajo realizado en este país, especialmente el que adelantó en Cali durante los más de veinte años que estuvo vinculado a la Universidad del Valle, le permitió las vivencias que él denomina escalofríos epistemológicos y le otorgó, además, la mayor experiencia como docente en un programa de Comunicación. 